\title{
Continuity and Change: Kyoto Chefs Engage with Science
}

\author{
Greg DE ST. MAURICE
}

University of Pittsburgh, Pittsburgh, PA 15260, USA

\begin{abstract}
Summary Kyoto's chefs have reacted proactively to changes brought about by the most recent phase of globalization, hoping to ensure the continued existence and resonance of Kyoto cuisine by using science to adapt it to contemporary circumstances. These chefs are breaking new ground in their pursuit of a scientific understanding of how Kyoto cuisine works. They meet once a month in a kitchen laboratory at Kyoto University to present and analyze culinary experiments in keeping with a predetermined theme. They use their acquired knowledge to more precisely hone their culinary skills and to explain Kyoto cuisine to a global audience. Chefs visit local elementary schools, appear on national television, and welcome chefs from abroad into their kitchens so that people across the world will better understand what authentic Kyoto cuisine consists of. Although these chefs' efforts are groundbreaking, there is also remarkable continuity to their approach. Not only has Kyoto cuisine always been in a steady state of transformation, but the chefs in the Laboratory are engaging with science and a global audience specifically so that they can ascertain Kyoto cuisine's continued existence and importance. Though their means of understanding and articulating what Kyoto cuisine is differs from that of their predecessors, concepts like shun (seasonality) and hin (refinement) still guide chefs today. Ultimately, then, based on interviews and participant observation conducted in and outside of the Japanese Cuisine Laboratory in 2012 and 2013, I argue that by engaging with contemporary food science, Kyoto's chefs achieve a strategic balance of protecting their culinary heritage while adapting it to contemporary circumstances.
\end{abstract}

Key Words cuisine, science, tradition, globalization

Kyo ryori (Kyoto cuisine) consists of a set of culinary traditions centered around Japan's pre-eminent tastemaking city, Kyoto. Scholars researching cuisine note how notoriously difficult it is to pin down and delimit a cuisine, particularly in today's interconnected world (1, 2). This said, Kyoto cuisine possesses certain characteristics for which it is well known. Important ingredients in Kyoto cuisine include Kyoto vegetables (e.g. the Shishigatani squash, Fig. 1), special fish like hamo (conger pike eel), and Kyoto's own soft water. Kyoto's chefs have mastered special cooking techniques like a bone-cutting technique (honekiri) for hamo and dashi (broth made from bonito and kelp) preparation. Among Kyoto's most iconic dishes are Kamo nasu no dengaku (Kamo eggplant with miso paste, Fig. 2) and saba zushi (pickled mackerel sushi, Fig. 3). The tableware used in Kyoto cuisine includes shikki (lacquerware), futamono (lidded bowls, Fig. 4), and iwaibashi (chopsticks used to partake of meals celebrating the new year). Special foods are also eaten on specific days, as with the adzuki bean and rice powder sweet minazuki, eaten at the end of June.

Recent decades have brought about new challenges for local foodways and culinary traditions, and Kyoto's are no exception $(3,4)$. Kyoto's chefs have responded by seeking to protect and promote Kyoto's agricultural and culinary heritage and taking Kyoto cuisine to the global stage. To this end, they have supported local

E-mail: gregdestmaurice@yahoo.com farmers growing heirloom vegetables, collaborated with chefs from abroad, and campaigned to have Japanese cuisine registered as a form of intangible cultural heritage by UNESCO. In an ongoing project, they have joined researchers in the Japanese Cuisine Laboratory at Kyoto University, each month presenting and analyzing culinary experiments in keeping with a predetermined theme such as satiety or bitterness.

This collaboration benefits both chefs and scientists. The application of scientific methods for acquiring knowledge helps chefs develop their understanding of how traditional cooking techniques work-highlighting interactions that occur when prescribed ingredients are combined or what a specific cooking technique accomplishes in a traditional recipe-and provides them with a language for explaining what is distinctive about Kyoto cuisine to their newfound global audience via a common vocabulary. Researchers examining Kyoto cuisine, meanwhile, uncover new knowledge about the transformation of ingredients into food, dishes, meals, and experiences at the hands of these master chefs, knowledge that may often be applicable beyond Kyoto.

Chefs in the Laboratory engage with science and a global audience so that they can ascertain Kyoto cuisine's continued existence and importance. Though their means of understanding and articulating what Kyoto cuisine is differs from that of their predecessors, concepts like shun (seasonality) and hin (refinement) still guide chefs today. Ultimately, then, based on interviews 


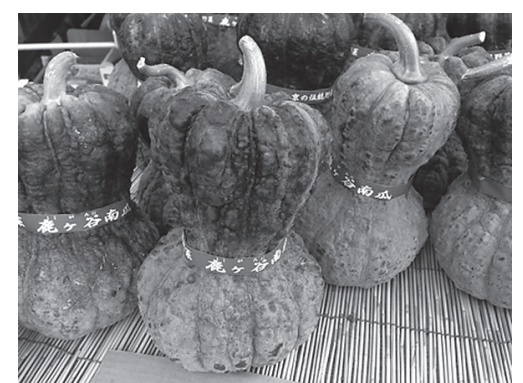

Fig. 1. The Shishigatani squash, a local heirloom variety.

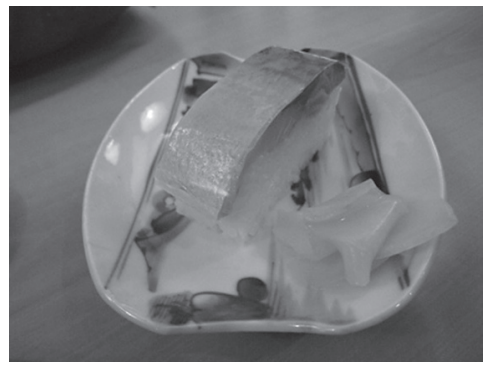

Fig. 3. Pickled mackerel sushi (saba zushi), a local specialty.

and participant observation conducted in and outside of the Japanese Cuisine Laboratory in 2012 and 2013, this paper argues that by engaging with contemporary food science, Kyoto's chefs protect their culinary heritage while adapting it to contemporary circumstances.

The Japanese Cuisine Laboratory thus holds lessons for chefs, government officials, and food activists across the world who wish to find ways to bolster culinary traditions and keep them relevant in the midst of a changing world. It also holds lessons for scientists interested in new means of understanding cooking, cuisine, and consumption from new and productive perspectives.

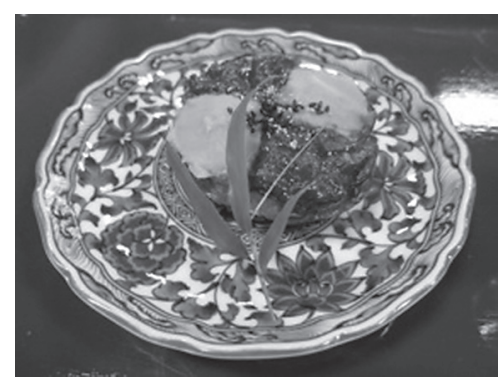

Fig. 2. Kamo eggplant, an heirloom vegetable, with two kinds of miso (Kamo nasu no dengaku).

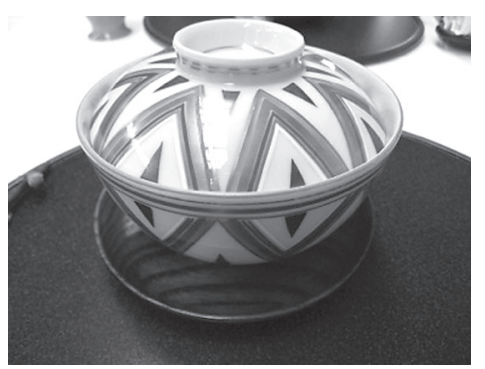

Fig. 4. A lidded bowl (futamono) used for a nimono (simmered course).

\section{REFERENCE}

1) Mintz SW. 1989. Cuisine and haute cuisine: How are they linked? Food Foodways 3: 185-190.

2) Appadurai A. 1988. How to make a national cuisine: Cookbooks in contemporary India. Comp Stud Soc Hist 30: 3-24.

3) Counihan C, Siniscalchi V. 2014. Food Activism: Agency, Democracy and Economy. Bloomsbury Academic, New York.

4) Brulotte RL, Di Giovine MA. 2014. Edible Identities: Food as Cultural Heritage. Ashgate, Burlington, VT. 